\title{
The Influence of Package Size and Flute Type of Corrugated Boxes on Load Bridging in Unit Loads
}

\author{
By Jonghun Park, ${ }^{1}$ Laszlo Horvath, ${ }^{1 *}$ Marshall S. White, ${ }^{1}$ Samantha Phanthanousy, ${ }^{1}$ \\ Philip Araman ${ }^{2}$ and Robert J. Bush ${ }^{1}$ \\ ${ }^{1}$ Department of Sustainable Biomaterials, Virginia Tech, Blacksburg, VA USA \\ ${ }^{2}$ Southern Research Station, USDA Forest Service, USA
}

\begin{abstract}
Shipping pallets often are designed with the assumption that the payload carried is flexible and uniformly distributed on the pallet surface. However, packages on the pallet can act as a series of discrete loads, and the physical interactions among the packages can add stiffness to the pallet/load combination. The term 'load bridging' has been used to describe this phenomenon. The study reported in this paper investigated the relationships of package size, corrugated flute type and pallet stiffness to load bridging and the resulting unit-load deflection. The experimental results indicated that an increase in box size changed the unit-load deflection by as much as $75 \%$. Flute type was found to impact load bridging and the resulting unit-load deflection. Changing the corrugated box flute type from B-flute or BC-flute to E-flute reduces the unit-load deflection by as much as $40 \%$. Also, experimental data indicates that the effect of package size and corrugated board flute type on pallet deflection is the greatest for low stiffness pallets. The results provide information that can be used to design unit loads that use material more efficiently. Copyright @ 2017 John Wiley \& Sons, Ltd.
\end{abstract}

Received 15 December 2015; Revised 4 November 2016; Accepted 18 November 2016

KEY WORDS: unit load; pallet; corrugated box; load bridging; stress distribution

\section{INTRODUCTION}

The international container trade industry moved 151 million TEUs (20-foot equivalent unit), including approximately 1.2 billion tons of dry goods in $2011 .^{1}$ Typically, goods are generally transported and stored in unit-load form at some point in the supply chain. The unit load is defined as 'a single item, a number of items, or bulk material which is arranged and restrained so that the load can be stored, picked up, and moved between two locations as a single mass'. ${ }^{2}$ A unit-load consists of loads (packages containing products) on a pallet with appropriate load stabilizers. The pallet, the most common unit-load platform, facilitates the transportation and storage of goods. While shipping pallets can be made from several materials (e.g. metal, paper and various plastics), wood is estimated to account for more than 90 percent of the U.S. pallet market. ${ }^{3}$ In 2011, approximately 416 million new wood pallets were manufactured in the United States. ${ }^{4}$ Among the various load types carried by the unit load, corrugated boxes are the most widely used packaging form for transporting goods in the United States. ${ }^{5}$ Although there are significant mechanical interactions between unit-load components as they move through supply chains, the components typically are designed independently, by different designers with limited communication between them. This results in added cost, reduced safety and considerable product damage. ${ }^{6}$ To overcome this limitation of supply chain design, research

\footnotetext{
* Correspondence to: Laszlo Horvath, Department of Sustainable Biomaterials, Virginia Tech, Blacksburg, VA 24061, USA.

E-mail: lhorvat@vt.edu
} 
into how pallets, packaging, unit load handling, storage and shipping equipment mechanically interact is necessary.

Although, numerous studies have investigated the effect of pallet design on packages, ${ }^{7-15}$ there is a lack of information regarding the effect of payload characteristics (boxes, drums, bags, etc.) on the performance of the pallet. When designing pallets, it is generally assumed that the payload is flexible and uniformly distributed on top of the pallet. However, packages on the pallet are acting as a series of discrete loads. The physical interaction between the packages on the pallet adds stiffness to the payload and causes the payload to bridge across the pallet supports, such as in warehouse storage racks. This load bridging can affect the deflection of the unit-load by redistributing the load from the center of the pallet to the supports and consequently decreasing the maximum bending moment experienced by the pallet. The effect of this load bridging is increased pallet payload capacity.

Two early studies ${ }^{16,17}$ examined the influences of various unit-load characteristics on load bridging, and found that stacking patterns and pallet stiffness significantly affected unit-load deflection. White ${ }^{18}$ confirmed that the deflection of the pallets was highly dependent on the types of packages (e.g. corrugated box, sacks, drums), stacking patterns and the type of load stabilizers (e.g. stretch wrap, strapping) that were used. Yoo et al. ${ }^{12}$ investigated the compressive stress distribution between corrugated boxes and the top surface of the pallet and quantified the redistribution of the compression stresses based on the stiffness of the package and the stiffness of the pallet top deck.

Although, there has been acknowledgement of load bridging, understanding of the complex interactions between the pallet and the types of payload, including the effect of packaging size, flute type of corrugated boxes and containment force of load stabilizers, is not documented. Lacking this knowledge, pallet design methodologies in use today are based on conservative adjustments for the effect of different types of loads carried by the pallet.

The objective of this study was to investigate the influence of rigid package size and flute type of corrugated boxes on the deflection of simulated unit-loads during warehouse rack storage.
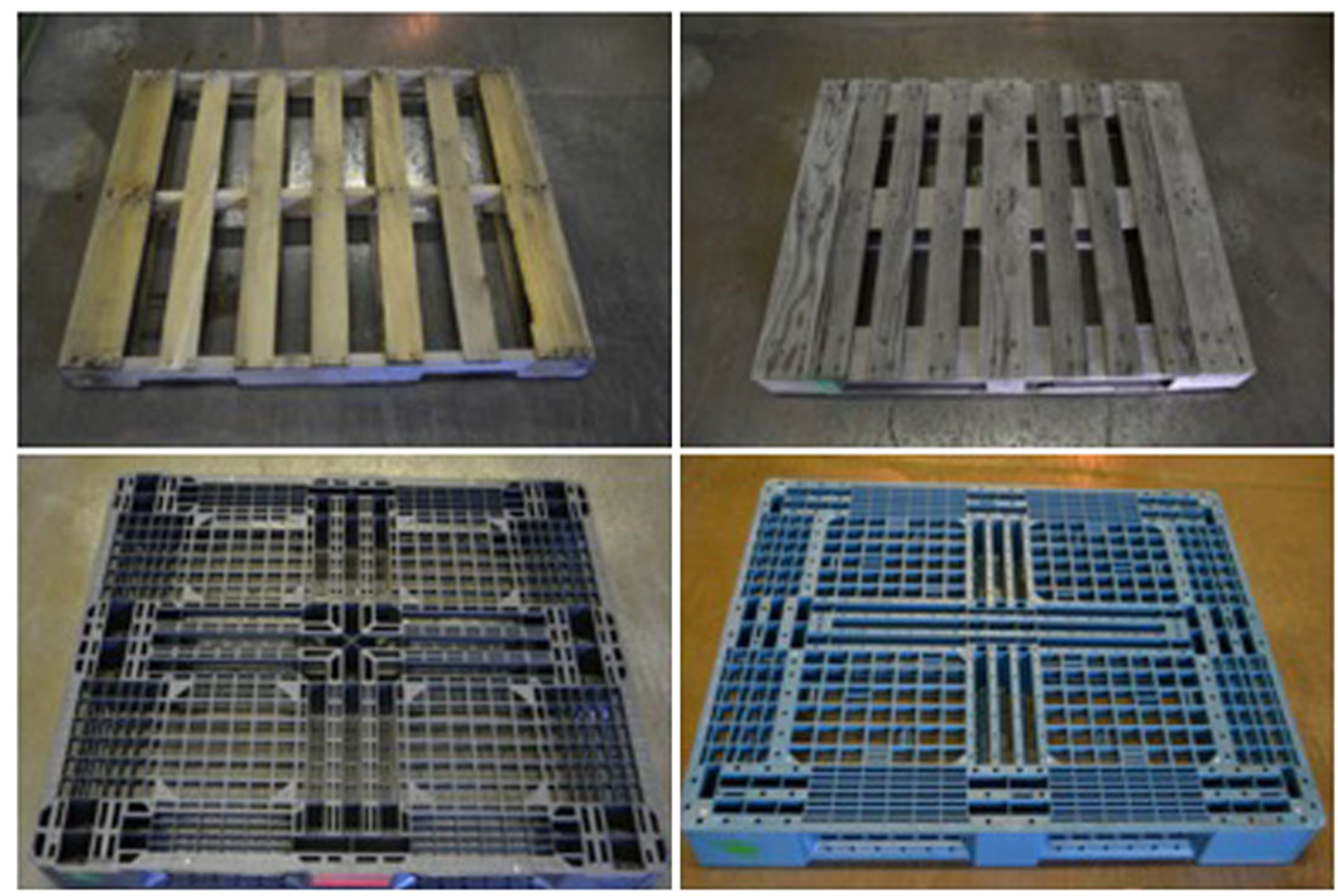

Figure 1. Commercial pallets representing the range in stiffness simulated by the pallet segments used in testing. Stringer class wood pallet made of Southern Pine (top-left), Block class wood pallet made of mixed hardwoods (top-right), Single-use plastic pallet made of recycled polypropylene (bottom-left) and Multiple-use plastic pallet made of polypropylene (bottom-right). 


\section{Limitations}

Because of the complexity of interactions occurring between unit load components, the following simplifications were necessary in order to study the phenomenon of interest.

- Only regular slotted type, corrugated boxes were investigated in the study.

- To isolate the effect of the size of corrugated boxes on the deflection of the pallet perpendicular to the supports, only a single row of corrugated boxes was investigated on a $1024 \mathrm{~mm} \times 254 \mathrm{~mm}$ pallet segment.

- Creep response of the pallet was ignored. Measurements of deflection were recorded immediately after load application.

\section{MATERIALS AND METHODS}

\section{Materials}

Simulated pallet segments. Four different commercial pallet designs were selected to represent the range of stiffness of pallet in use (Figure 1). The specifications of the pallets are presented in Table 1. The bending stiffness values of the four pallets were measured by a three-point bending test, using a fixed platen compression tester (Tinius Olsen). The pallets were suspended across their width on two $50 \mathrm{~mm}$ diameter, circular, beams, spaced $914 \mathrm{~mm}$ apart. An additional circular load beam was centered on the top of the pallet and was loaded by the top platen of the compression tester. The deflection of the pallet was measured by a string potentiometer (UniMeasure, Model P510-5-S3) at the center of the bottom deck of the pallet. The bending stiffness of the pallets were adjusted to represent the stiffness of a $1016 \mathrm{~mm} \times 254 \mathrm{~mm}$ segment of the pallet, by dividing the measured stiffness of the whole pallet by the ratio of the actual width of the pallet and the $254 \mathrm{~mm}$ width of the pallet section (Table 1).

Three $1016 \mathrm{~mm} \times 254 \mathrm{~mm}$ wooden boards were prepared to simulate the low, medium and high stiffness range of the investigated pallets. The characteristics of these pallet segments are in Table 1.

Corrugated boxes. Regular slotted (RSC) type corrugated boxes with three different outside dimensions $(508 \mathrm{~mm} \times 254 \mathrm{~mm} \times 254 \mathrm{~mm}, 254 \mathrm{~mm} \times 254 \mathrm{~mm} \times 254 \mathrm{~mm}, 127 \mathrm{~mm} \times 254 \mathrm{~mm} \times 254 \mathrm{~mm})$ and flute types (E, B and BC) were used for this study. The boxes were manufactured and shipped flat by Packaging Corporation of America, Roanoke, Virginia, USA. Flat crush test according to TAPPI 825 (2009) was conducted to determine the flat crush strength and stiffness of each flute type used for this study. Table 2 contains the physical properties of the corrugated boxes.

The boxes were erected using a custom jig to ensure that each edge formed a $90^{\circ}$ angle. Rigid oriented strand board (OSB) boxes manufactured using $13 \mathrm{~mm}$ thick OSB board, of the exact inside dimensions of the corrugated box, were placed inside of the corrugated box. The OSB boxes were filled with weights, and a lid was secured to the top to seal the box. The flaps of the corrugated box

Table 1. The relative stiffness of commercial pallets and simulated pallet segments investigated in this study (adjusted for the difference in width).

\begin{tabular}{|c|c|c|c|}
\hline Pallets & Material & Dimension $(\mathrm{L} \times \mathrm{W})$ & $\begin{array}{l}\text { Adjusted bending } \\
\text { stiffness }\end{array}$ \\
\hline Block class wood pallet & Mixed hardwoods & $1219 \mathrm{~mm} \times 1016 \mathrm{~mm}$ & $13 \mathrm{~kg} / \mathrm{mm}$ \\
\hline Multiple-use plastic pallet & Polyethylene & $1219 \mathrm{~mm} \times 1016 \mathrm{~mm}$ & $7 \mathrm{~kg} / \mathrm{mm}$ \\
\hline Stringer class wood pallet & Southern Pine & $1219 \mathrm{~mm} \times 1016 \mathrm{~mm}$ & $5 \mathrm{~kg} / \mathrm{mm}$ \\
\hline Single-use plastic pallet & $\begin{array}{c}\text { Recycled } \\
\text { polyethylene }\end{array}$ & $1130 \mathrm{~mm} \times 978 \mathrm{~mm}$ & $1 \mathrm{~kg} / \mathrm{mm}$ \\
\hline Simulated pallet segments & & Dimension $(\mathrm{L} \times \mathrm{W})$ & Bending stiffness \\
\hline High stiffness (19 mm) Spruce solid wood) & & $1016 \mathrm{~mm} \times 254 \mathrm{~mm}$ & $9 \mathrm{~kg} / \mathrm{mm}$ \\
\hline Medium stiffness $(19 \mathrm{~mm})$ Birch plywood & & $1016 \mathrm{~mm} \times 254 \mathrm{~mm}$ & $5 \mathrm{~kg} / \mathrm{mm}$ \\
\hline Low stiffness (13 mm) Birch plywood) & & $1016 \mathrm{~mm} \times 254 \mathrm{~mm}$ & $2 \mathrm{~kg} / \mathrm{mm}$ \\
\hline
\end{tabular}


Table 2. Description of the filled corrugated boxes used in the load-bridging tests.

\begin{tabular}{|c|c|c|c|c|c|c|}
\hline \multirow{2}{*}{$\frac{\text { Box size }}{(\mathrm{L} \times \mathrm{W} \times \mathrm{H})}$} & \multirow{2}{*}{$\begin{array}{l}\text { Weight } \\
\text { per box } \\
(\mathrm{kg})^{\mathrm{a}}\end{array}$} & \multirow{2}{*}{$\begin{array}{l}\text { Flute } \\
\text { type }\end{array}$} & \multicolumn{2}{|c|}{ Flat crush test ${ }^{3}$} & \multirow{2}{*}{$\begin{array}{l}\text { Nominal } \\
\text { edge } \\
\text { crush test } \\
\text { values }^{2} \\
(\mathrm{kN} / \mathrm{m})\end{array}$} & \multirow{2}{*}{$\begin{array}{l}\text { Caliper } \\
(\mathrm{mm})\end{array}$} \\
\hline & & & $\begin{array}{l}\text { Average strength } \\
\qquad(\mathrm{kPa})\end{array}$ & $\begin{array}{l}\text { Average elastic } \\
\text { modulus, unused } \\
\text { material }(\mathrm{N} / \mathrm{mm})\end{array}$ & & \\
\hline \multirow[t]{3}{*}{$127 \mathrm{~mm} \times 254 \mathrm{~mm} \times 254 \mathrm{~mm}$} & 4.54 & $\mathrm{E}$ & $549(11 \%)$ & $25.7(19 \%)$ & 5.6 & 1.78 \\
\hline & & B & $292(18 \%)$ & $2.9(37 \%)$ & 5.6 & 2.80 \\
\hline & & $\mathrm{BC}$ & - & - & 8.5 & 6.22 \\
\hline $254 \mathrm{~mm} \times 254 \mathrm{~mm} \times 254 \mathrm{~mm}$ & 9.10 & $\mathrm{~B}$ & $292(18 \%)$ & $2.9(37 \%)$ & 5.6 & \\
\hline $504 \mathrm{~mm} \times 254 \mathrm{~mm} \times 254 \mathrm{~mm}$ & 18.10 & $\mathrm{~B}$ & $292(18 \%)$ & $2.9(37 \%)$ & 5.6 & \\
\hline
\end{tabular}

Notes: values in parentheses are percent coefficient of variance values.

${ }^{1}$ All weight and dimensions are converted from American Standard units.

${ }^{2}$ The Edge Crush Test values are the nominal published values by the manufacturer.

${ }^{3}$ The Flat Crush Test was conducted based on TAPPI 825 (2009) using 10 replicates.

were sealed using hot melt adhesive. The assembled boxes were conditioned at $23^{\circ} \mathrm{C}$ and $50 \%$ relative humidity for at least $72 \mathrm{~h}$ according to ASTM D 4332 (2006).

\section{Testing methods}

Simulated unit-load bending tests using filled corrugated boxes. Figure 2 shows the detailed experimental test setup. The $1016 \mathrm{~mm} \times 254 \mathrm{~mm}$ simulated pallet segments were supported using two $102 \mathrm{~mm} \times 102 \mathrm{~mm}$ I-beams with $51 \mathrm{~mm}$ overlap at each end, leaving $914 \mathrm{~mm}$ free span between the beams. To measure the deflection of unit-loads, two Linear Variable Differential Transformers (LVDTs) were secured to two custom yokes, and were placed centrally on both sides of the simulated pallet segment. Three layers of corrugated boxes were placed on the simulated pallet segment covering the entire length of the pallet segment. A total of six $508 \mathrm{~mm} \times 254 \mathrm{~mm} \times 254 \mathrm{~mm}$ boxes, twelve $254 \mathrm{~mm} \times 254 \mathrm{~mm} \times 254 \mathrm{~mm}$ boxes and twenty-four $127 \mathrm{~mm} \times 254 \mathrm{~mm} \times 254 \mathrm{~mm}$ boxes were placed on the pallet segments. The overall weight of the filled boxes for the segment bending tests was $109 \mathrm{~kg}$. One floor jack was positioned under the center of the simulated pallet segment to prevent deflection during the loading of the corrugated boxes. A dial gauge was placed $50 \mathrm{~mm}$ from the center on the simulated pallet segment to ensure that the specimen was level. Following the loading of the corrugated boxes onto the pallet segment, the floor jack was slowly removed to simulate the storage rack support condition. The deflection of the segment was measured for 1 min using the LabView ${ }^{\circledR}$

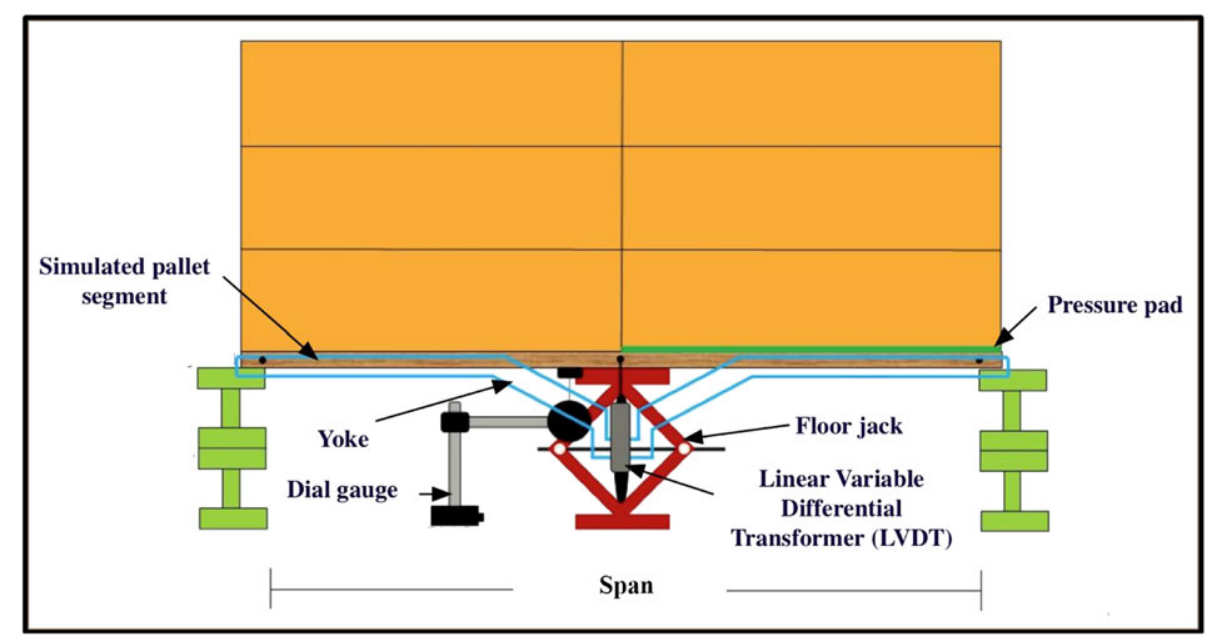

Figure 2. Experimental setup for unit-load/pallet segment, bending tests showing the location of the pressure pad. 
software and two LVDTs. Following the first test, the boxes were removed, and the stack was reassembled by alternating the bottom layer two additional times. The entire experiment was repeated three additional times, using new boxes each time. This resulted in a total number of nine replications for the size effect and three replications for the flute effect. All tests were conducted inside an environmental chamber at $23^{\circ} \mathrm{C}$ and $50 \%$ relative humidity

Pressure distribution mapping. A Tekscan pressure measurement system, including a pressure mat (Model 5315), was used to measure the pressure distribution between the packages and the simulated pallet segments during the bending test. The pressure mat was equilibrated using a Tekscan equilibrator (Model PB100F) and calibrated using a two-point calibration from $7 \mathrm{kpa}$ to $21 \mathrm{kpa}$. The pressure mat system was connected to an $I-S c a n \circledR$ data acquisition software program that recorded the pressure obtained from each pressure sensors (sensel) of the mat between 0 and $34 \mathrm{kpa}$, in real time. For the bending test, the pressure mat was placed between the simulated pallet segment and the corrugated boxes. It covered one half of the simulated pallet segment, from the outer edge to the center. Two images were taken during the bending test, one image of the pressure distribution at the beginning of the test and a second image after the floor jack was removed. Figure 2 shows the detailed experimental setup.

\section{Experimental design and statistical analysis}

The experimental design to analyze the effect of package geometry and flute type on pallet deflection is provided in Table 3. Two separate, two-way analyses of variance (ANOVA) were used to investigate the effects of packaging size and flute type on the unit-load deflection using simulated pallet segments with different stiffness values. A Simple Main Effects test was conducted to investigate the interaction between packaging size and simulated pallet segment stiffness and between flute type and simulated pallet segment stiffness. Post-hoc analysis was conducted using Tukey's HSD to check the level of difference among the different treatment levels. A statistics software, SAS® JMP®, was used for conducting the statistical analysis.

\section{RESULTS AND DISCUSSION}

\section{The effect of package size on pallet segment deflection}

Table 4 provides the average simulated unit-load deflections as a function of different package sizes and box flutes for the three simulated pallet segments. Figure 3 shows the relative changes in the unit-load deflections as a function of the flute type, package size and stiffness of simulated pallet segments. The deflection of the pallet segment supporting a uniform load was calculated using Equation 1 as a simply supported beam.

$$
\delta=\frac{5 W L^{4}}{384 E I}
$$

where: $\delta$ is maximum deflection (mm), $W$ is uniform load per unit length $(107 \mathrm{~g} / \mathrm{mm}), L$ is the span

Table 3. Experimental design to investigate the effect of corrugated box size and flute type on pallet deflection.

\begin{tabular}{lcccc}
\hline Simulated pallet segments & Box size & E-flute & B-flute & BC-flute \\
\hline High stiffness & $127 \mathrm{~mm} \times 254 \mathrm{~mm} \times 254 \mathrm{~mm}$ & 3 replicates & 9 replicates & 3 replicates \\
& $254 \mathrm{~mm} \times 254 \mathrm{~mm} \times 254 \mathrm{~mm}$ & - & 9 replicates & - \\
Medium stiffness & $508 \mathrm{~mm} \times 254 \mathrm{~mm} \times 254 \mathrm{~mm}$ & - & 9 replicates & - \\
& $127 \mathrm{~mm} \times 254 \mathrm{~mm} \times 254 \mathrm{~mm}$ & 3 replicates & 9 replicates & 3 replicates \\
& $254 \mathrm{~mm} \times 254 \mathrm{~mm} \times 254 \mathrm{~mm}$ & - & 9 replicates & - \\
Low stiffness & $508 \mathrm{~mm} \times 254 \mathrm{~mm} \times 254 \mathrm{~mm}$ & - & 9 replicates & - \\
& $127 \mathrm{~mm} \times 254 \mathrm{~mm} \times 254 \mathrm{~mm}$ & 3 replicates & 9 replicates & 3 replicates \\
& $254 \mathrm{~mm} \times 254 \mathrm{~mm} \times 254 \mathrm{~mm}$ & - & 9 replicates & - \\
\hline
\end{tabular}




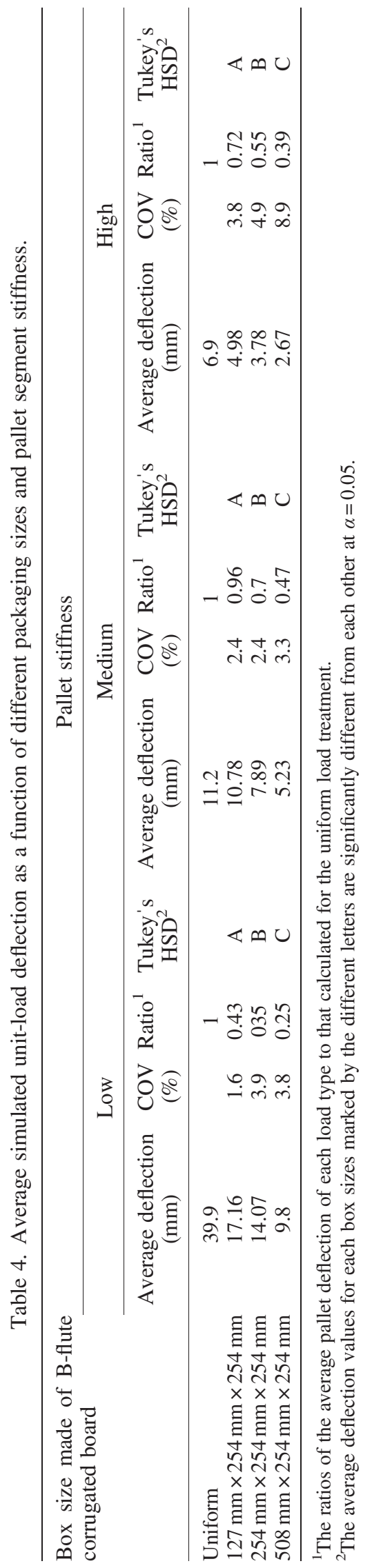




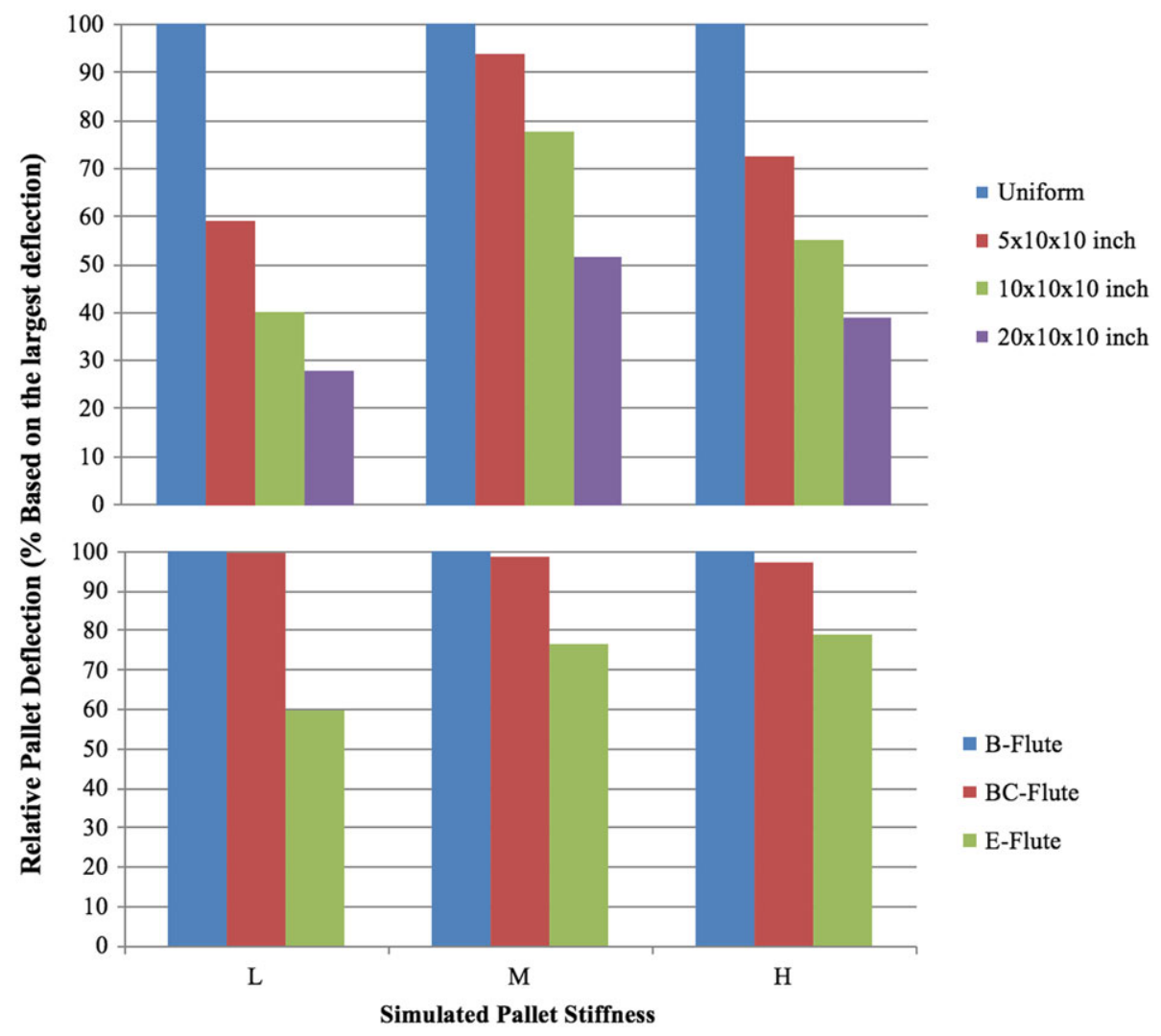

Figure 3. Relative change in the simulated pallet deflection as a function of the corrugated board flute type, packaging size and stiffness of simulated pallet.

$(914 \mathrm{~mm}), E$ is modulus of elasticity, EI (Low stiffness simulated pallet segment: $30 \times 10^{3} \mathrm{MPacm}^{4}$, medium stiffness simulated pallet segment: $86.1 \times 10^{3} \mathrm{MPacm}^{4}$, high stiffness simulated pallet segment: $140.510^{3} \mathrm{MPacm}^{4}$ ).

Both package size and box flute significantly affected the unit-load deflection ( $p$-value $<0.0001$ ). Statistically significant treatment effects based on Tukey's HSD test are shown in Tables 4 and 5 as the letters $\mathrm{A}, \mathrm{B}$ and $\mathrm{C}$.

As the size of the package increased, there was a significant reduction in the deflection of the pallet segment. As box length increased from $124 \mathrm{~mm}$ to $254 \mathrm{~mm}$ and to $508 \mathrm{~mm}$, the low stiffness pallet segment deflection, decreased by 57\%, 65\% and 75\%, respectively. Similar deflection trends were observed when testing the medium and high stiffness pallet segments. The deflection of medium stiffness pallet segment deflection decreased by $4 \%, 30 \%$ and $53 \%$, and high stiffness pallet segment decreased by $28 \%, 45 \%$ and $61 \%$. The results indicated that the effect of package size is more prominent for the lower stiffness pallet. However, contrary to the findings of earlier studies by White et al. ${ }^{8}$ and Collie et al., ${ }^{7}$ this study did not find an linear correlation between the pallet stiffness and load bridging.

Figure 4 shows the distribution of compression stresses on the three pallet segments by the three package sizes, following the load application. The red color denotes high compression stresses. As the packaging size increased, more stress was concentrated at the edges of the simulated pallet segments where the I-beams provided full support to the load. The larger boxes redistribute the forces away from the center of the pallet segment to the supports. This redistribution of forces away from the center of the segment resulted in less deflection and confirms the mechanism of load bridging on pallets. 
Table 5. Average simulated unit-load deflection as a function of different flute types and pallet stiffness.

\begin{tabular}{|c|c|c|c|c|c|c|c|c|}
\hline \multirow{3}{*}{$\begin{array}{l}\text { Flute type for } \\
127 \mathrm{~mm} \times 254 \mathrm{~mm} \times 254 \mathrm{~mm} \\
\text { box }\end{array}$} & \multicolumn{8}{|c|}{ Pallet stiffness } \\
\hline & \multicolumn{3}{|c|}{ Low } & \multicolumn{3}{|c|}{ Medium } & \multicolumn{2}{|c|}{ High } \\
\hline & $\begin{array}{l}\text { Average } \\
\text { deflection } \\
\quad(\mathrm{mm})\end{array}$ & $\begin{array}{c}\mathrm{COV} \\
(\%)\end{array}$ & $\begin{array}{l}\text { Turkey } \\
\text { 's } \\
\text { HSD }^{1}\end{array}$ & $\begin{array}{l}\text { Average } \\
\text { deflection } \\
(\mathrm{mm})\end{array}$ & $\begin{array}{c}\mathrm{COV} \\
(\%)\end{array}$ & $\begin{array}{l}\text { Tukey } \\
\text { 's } \\
\text { HSD }^{1}\end{array}$ & $\begin{array}{l}\text { Average } \\
\text { deflection } \\
\quad(\mathrm{mm})\end{array}$ & $\begin{array}{l}\text { COV Tukey } \\
(\%) \text { 's } \\
\text { HSD }^{1}\end{array}$ \\
\hline B & 17.16 & 3.0 & A & 9.56 & 3.1 & $\mathrm{~A}$ & 4.98 & $9.4 \mathrm{~A}$ \\
\hline $\mathrm{BC}$ & 17.12 & 0.4 & A & 9.68 & 2.2 & A & 4.84 & $0.8 \mathrm{~A}$ \\
\hline $\mathrm{E}$ & 10.23 & 2.6 & $\mathrm{C}$ & 7.35 & 0.7 & B & 3.93 & $0.7 \mathrm{~B}$ \\
\hline
\end{tabular}

${ }^{1}$ The average deflection values for each box sizes marked by the different letters are significantly different from each other at $\alpha=0.05$.

\section{The effect of corrugated flute type on pallet segment deflection}

Box compression failures include the flat crushing of the flutes. Therefore, the flat crush strength and initial modulus of the corrugated medium may influence the distribution of the load across the pallet deck. In Table 2 are the flat crush strengths and initial modulus of the E and B-flute corrugated paperboard using the TAPPI standard flat crush compression test. The strength and initial modulus values are not presented for BC-flute because the test described in TAPPI T825 standard cannot be used to measure the values with any reliability because of the undesired lateral motion of the central liner. The E-flute corrugated board had $88 \%$ greater strength and almost nine-fold greater initial modulus then the B-flute corrugated board.

In Table 5 are the results of the pallet segments bending tests supporting the 127 -mm-long boxes made of the three different flute types. The results indicate that flute type does influence the load distribution across pallet decks. The pallet segments supporting the E-flute boxes deflected an average of 20 to $40 \%$ less than those segments supporting the B and BC-flute boxes. The effect is greatest on the low stiffness pallet segment and cannot be explained by the very small difference in the internal box dimensions. However, it might be the consequence of the difference in flat crush compression initial modulus and strength. There was no difference in the pallet segment deflections supporting the B and $\mathrm{BC}$-flute boxes which might indicate that the behavior of the $\mathrm{BC}$-flute board is driven by the properties of the B-flute member. A possible explanation is shown schematically in Figure 5. The way the flutes are expected to compress during an evenly loaded testing scenario and the pallet segment

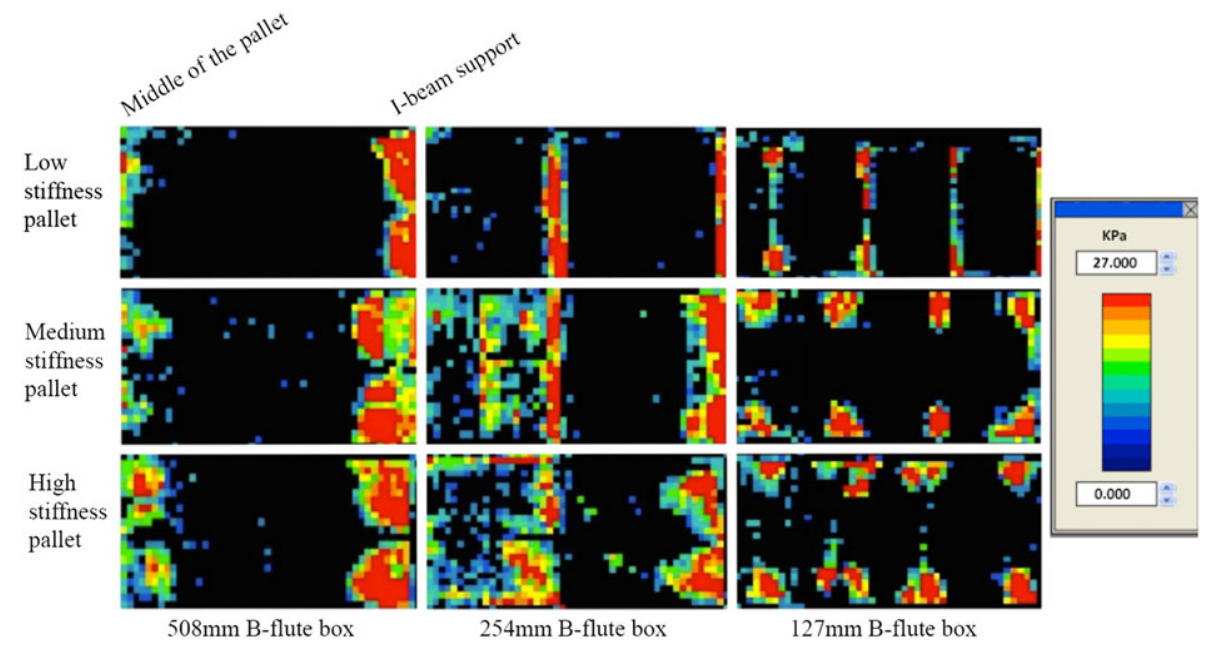

Figure 4. Compression stress distribution between the packages and the simulated pallet segments using different sizes of packages: The left side of the image shows the middle section of the simulated pallet segment, and the right side of the image shows the end of the simulated pallet segment supported

by a rack. 


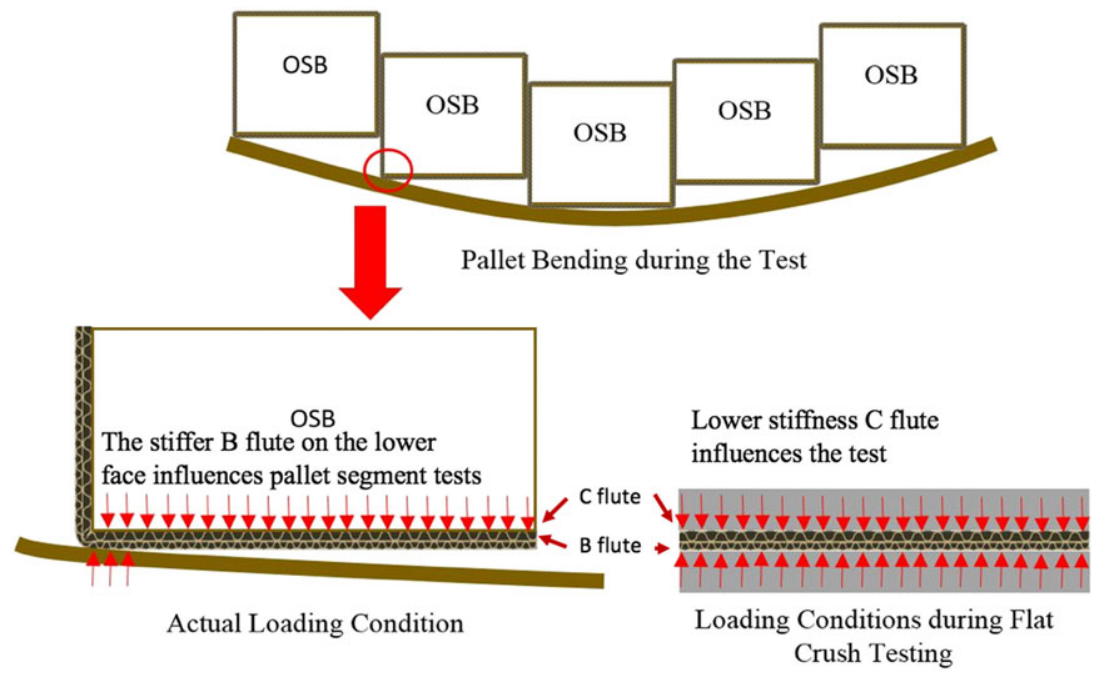

Figure 5. Compression of the bottom of the corrugated box during actual loading conditions and during flat crush testing.

bending test are very different. During an evenly loaded testing scenario, both flute layers are compressed uniformly over the entire specimen, between two rigid platens. This is shown in the lower right of Figure 5. The lower flat crush initial modulus and strength of the C-flute in the BC-flute laminated structure is determining the test results. However, when the double wall corrugated is compressed during the pallet segment bending tests, the compression stresses are concentrated at the bottom edge of the box because of pallet segment deflection. It is the B-flute layer that is being compressed by the pallet deck, as shown in the lower left of the figure. Therefore, it is not surprising that the B and BC-flute would influence the pallet segment deflection, similarly. This is confirmed by comparing the compression stress distribution in the images in Figure 6. The compression stresses in the center of the segments (circled in the left of each image) are compressing less for the E-flute box than either for the B or BC-flute boxes. This is most easily seen in the images of the medium and high stiffness pallet segments.

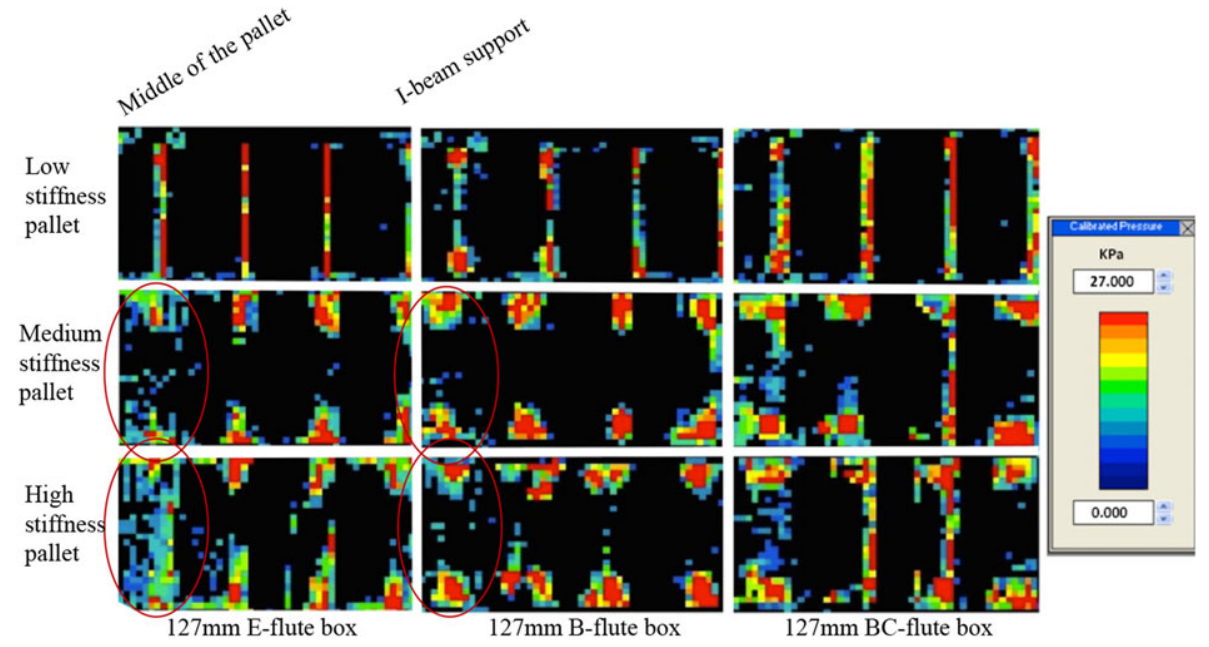

Figure 6. Compression stress distribution of between the packages and the simulated pallet segments using corrugated boxes with different flute types. The left side of the image shows the middle section of the simulated pallet segment, and the right side of the image shows the end of the simulated pallet segment supported by a rack. 
Standard pallet bending strength tests, as described in ASTM D1185 or ISO 8611 is commonly used to determine the load capacity of pallets. The load capacity of pallets is a function of the stiffness of the pallet which is characterized by pallet deflection and the strength of the pallet that is characterized by structural failure. When the load carrying capacity of a pallet is limited by its stiffness, it is clear from this research, that increasing the size of the package and changing the flute, can increase the load capacity of the pallet by as much as $75 \%$. However, the extent to which package size and flute will influence the capacity of medium to high stiffness pallets must be determined by failure tests.

\section{CONCLUSION}

1 Increasing the size of packages led to a significant decrease in pallet segment deflection. The package size effect on pallet deflection was the greatest for the low stiffness simulated pallet segments. For the medium stiffness pallet segment, which was comparable to a stringer class wood pallet, deflection of the simulated unit load decreased by $4 \%, 30 \%$ and $53 \%$, when package length increased from $127 \mathrm{~mm}$ to $254 \mathrm{~mm}$ and to $508 \mathrm{~mm}$, respectively.

2 Corrugated flute type significantly affects deflection of the pallet segments. This seems to be related to the flat compression strength and initial modulus of the flutes or medium. Pallet segment deflection was significantly less when supporting the stronger and stiffer E-flute boxes. For the medium stiffness pallet segment, which was comparable to a stringer class wood pallet, pallet deflection decreased by $23 \%$, when B-flute corrugated boxes were changed to the E-flute boxes. There was no difference between the B-flute and BC-flute tests. However, it was clear, that during the pallet segment bending tests, the double wall flat crushing interaction with the pallet deck was determined by the B-flute layer, and therefore it was not surprising that the B and BC-flute test results were similar.

3 Pressure measurements at the interface between the packaging and the pallet segments confirmed the mechanism of load redistribution by packaging. The pressure decreased at the center of the simulated pallet segment and increased at the end of the simulated pallet segment as the package size increased and the pallet segment stiffness decreased. This redistribution of compression stresses towards the ends of the simulated pallet segments explained the lower pallet segment deflections. In order to avoid damaging the packaging during storage in rack systems, packaging engineers must consider the effects of these changes in the pallet and packaging characteristics on the stress concentrations at the pallet/package interface.

Standard pallet bending strength tests, as described in ASTM D1185 or ISO 8611 are commonly used to determine the load capacity of pallets. Load capacity is the function of the stiffness of the pallet (characterized by pallet deflection) and the strength of the pallet (characterized by structural failure). When the load carrying capacity of a pallet is limited by its stiffness, it is clear from this research, that increasing the size of the package and changing the flute, can increase the load capacity of the pallet by as much as $75 \%$. However, the extent to which package size and flute type will influence the capacity of medium to high stiffness pallets must be determined by failure tests.

\section{ACKNOWLEDGEMENTS}

USDA Forest Service - Southern Research Station, Ongweoweh Corporation and the members of the Center for Packaging and Unit Load Design at Virginia Tech are gratefully acknowledged for their financial support for this research project. Packaging Corporation of America (PCA) is also acknowledged for the testing material support for this research project.

\section{REFERENCES}

1. UNCTAD. Review of Maritime Transport. United Nations Conference on Trade and Development (UNCTAD). United Nations Publication: Geneva, Switzerland, 2012. 
2. White MS, Hamner P. Pallets move the world: the case for developing system-based designs for unit loads. Forest product journal 2005; 55: 8-16.

3. Trebilcock B. Talking pallets with modern readers. Modern Materials Handling 2013; 68: 26-34.

4. Araman PA, Bush RJ. New and Used Pallet Information Plus Other Topics. Presentation at Western Pallet Association Annual Meeting: Rancho Mirage, CA, USA, 2015.

5. Twede D, Selke S. "Cartons, Crates and Corrugated Board Handbook of Wood and Paper Packaging. DEStech Publications, Inc: Lancaster, PA, USA, 2004.

6. White MS. The effect of mechanical interactions between pallets and packaging on packaging costs. Paper and Presentation at the ISTA Dimensions.05 meeting. March 8-11, Orlando, FL, USA. 2005.

7. Ievans UI. Effect of warehouse mishandling and stacking patterns on compression strength of corrugated boxes. Tappi 1975; 58(8): 108-111.

8. Monaghan J., Marcondes J. Overhang and pallet gap effects on the performance of corrugated fiberboard boxes. Transactions of the ASAE USA, 1992; DOI: .13031/2013.28820.

9. DiSalvo MH. Interactive effects of palletizing factors on fiberboard packaging strength. M.S. Thesis San Jose State Univ. $1999 ;$

10. Singh SP, Singh J, Saha K. Effect of palletized box offset on compression strength of unitized and stacked empty corrugated fiberboard boxes. Journal of Applied Packaging Research 2011; 5(3): 157-167.

11. Singh SP, Singh J, Saha K, Chonchenchob V. Effect of lateral box offset and pallet overhang on compression strength of stacked fiberboard boxes and impact on stability. Journal of Applied Packaging Research 2012; 6(3): 129-148.

12. Han J, White MS, Hamner P. Development of a finite element model of pallet deformation and compressive stresses on packaging within pallet loads. Journal of Applied Packaging Research 2007; 1(3): 129-148.

13. Yoo J. Quantitative analysis of the compressive stress distributions across pallet decks supporting packaging in simulated warehouse storage. In M.S. Thesis Department of Wood Science and Forest Products. Virginia Tech.: Blacksburg, VA, USA, 2008.

14. Yoo J. Modeling compressive stress distributions at the interface between a pallet deck and distribution packaging. In Diss. Department of Wood Science and Forest Products. Virginia Tech.: Blacksburg, VA, USA, 2011.

15. Baker M, Horvath L, White MS. Effect of pallet deckboard stiffness on corrugated box compression strength. Journal of Packaging Technology and Science 2016; 29(4-5): 263-274. DOI: 10.1002/pts.2201

16. Fegan B. Load-support conditions and computerized test apparatus for wood pallets. In Department of Wood Science and Forest Products. Virginia Tech: Blacksburg, VA, USA, 1982.

17. Collie S. Laboratory verification of pallet design procedures. In M.S. Thesis, Department of Wood Science and Forest Products. Virginia Tech: Blacksburg, VA, USA, 1984.

18. White MS, Dibling W, Rupert R, McLeod J. Determination of pallet maximum working loads from nominal load measurements. In Center for Unit Load Design. Virginia Tech: Blacksburg: VA, USA, 1999. 